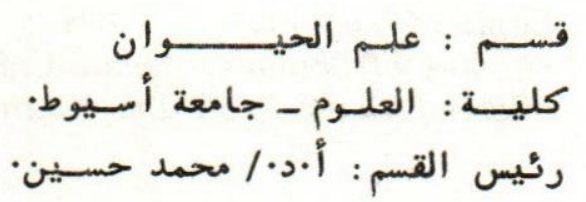

دراسات على العضلات خلـف الجمجمة

لثعبان ابو السيور بساموفيس سيبيلانس • رتبة: اوفيديا _ عائلة : كولبريدى

مـ تعليقات على العضلات السابق وصفها في البحوث الأربعة

عبد الحميد خليـل · محمــ ومبـة ، ماجــه الشابورى

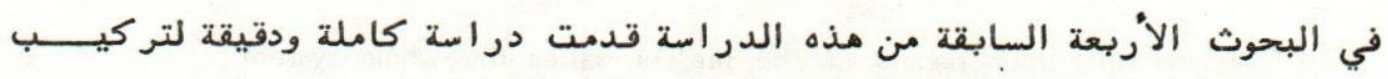

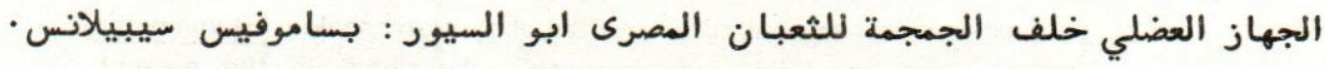

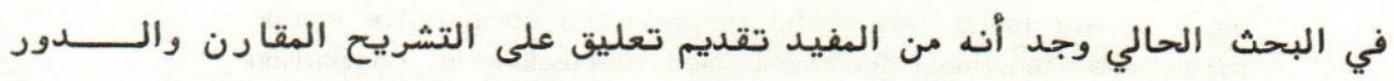

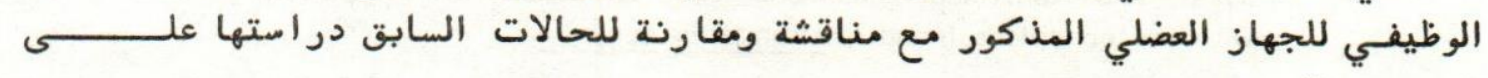

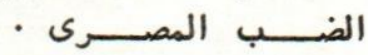


Dept. of Zoology,

Faculty of Science, Assiut University,

Head of Dept. Prof. Dr. M. Hussein.

\title{
STUDIES ON THE POST-CRANIAL MYCOLOGY OF PSAMMOPHIS SIBILANS (LINNAEUS), ORDER:OPHIDIA, FAMIL Y:COLUBRIDAE V- COMMENTS ON THE MUSCLES DESCRIBED IN THE FIRST FOUR PAPERS OF THE PRESENT SERIES INCLUDING A COMPARISON WITH THE CASE OF LIZARDS
}

\author{
By \\ A. KHALIL; M.T. WAHBA and M.R. EL-SHABOURY \\ (Received at 24/7/1986)
}

\begin{abstract}
SUMMARY
In the first four papers of the present series the whole system of post-cranial musculature of the Egyptian snake Psammophis sibilans were carefully and accurately described. In the present paper it was found very useful to present a comparative anatomical and functional comment and discussion in comparison with the conditions found in Uromastyx aegyptia.
\end{abstract}

\section{COMMENTS and DISCUSSION}

The snake subject of the present study is characterized by the complete loss of the girdles and limbs. Hence, the only muscles remaining are the axial muscles, which extend longitudinally parallel to the longitudinal axis of the body and are atached by both ends to the axial skeletal elements. Of those muscles, twenty four items were considered in the findings. However, the muscles named masticatory one (Mas. 1) and masticatory two (Mas. 2) are not typical post-cranial muscles, but they are considered in the present work to be cranial muscles, although their origins are peculiarly shifted posteriorly to be located in the places of origins of the trapezius (30) and latissimus (38) of lizards (KHALIL, et al. 1977). In fact, when exposing those two muscles for the first time, one could easily think that the trapezius and latissimus are found in snakes, but when one explores the insertions and functions of those two muscles one can easily come to the conclusion that those two muscles are cranial masticatory muscles which have posteriorly shifted their places of origin. A third muscle, was identified as the dermo-quadrate (sternocleidomastoid, muscle numbered 8 of lizards) (KHALIL, et al. 1977). In the case of lizards, the latter muscle originates on the pectoral girdle and is inserted on the processus parietalis, but in the case of the snake studied it originates on the dorso-lateral scales and is inserted on the quadrate. However, the place of origin of that muscle on the dorso-lateral scales is opposite to its insertion on the pectoral girdle present in lizards, and the place of insertion of that muscle on the quadrate bone of the snake studied is in the same locality of insertion of that muscle on the processus parietalis when it is present in lizards. Concequently, the homology established in the present work is safe enough. Other muscles which are described in the present work are those attached to the ventral and lateral scales. Those muscles can be classified into three groups. The first group of muscles (a) are called the (intercutali) and they connect each ventral scale with the one infront and the other one behind. The second group of muscles (b) are called the (squamasquali), and they connect each ventral scale with an anterior lateral scale. The third group of muscles (c) connect the successive lateral scales and are called (intersquamali). 


\section{A. KHAL Il, et al.}

Those terms are used after Du Angus BELLAIRS (1969). Those interscalar muscles have apparantly a definite role in the mechanism of movement.

Of the twenty four axial muscles mintioned in the present series of papers, only twenty two muscles can be considered as typical axial post-cranial muscles. Of those twenty two muscles, fourteen can be easily homologized with their opposite muscles in lizards. Those muscles are, the cranio-spinal (1), inner semispinal (2), dermo-quadrate (sternocleidomastoid 8), costo-vertebral (9), cranioatlas (lateral cranio-vertebral 10), medio and latero-ventral cranio-vertebral (ventral cranio-vertebral 13), outer semispinal (15), dermo-costal (16), ilio-costal (17), supracostal and intercostal (18), transverse abdominal (23), subcostal (24) and the caudal myotomes (25). In the case of the snake examined those muscles are given the same numbers used in lizards (KHALIL, et al. 1977). The rest of the muscles of the snake described are given numbers starting by OP. (ophidian). Those remaining eight muscles are the intervertebral (OP.1), median intervertebro-articular (OP.2), lateral intervertebro-articular (OP.3), dorsal costo-vertebral (OP.4), outer and inner costo-cutaneous (OP.5), interscalar muscles (OP.6), ventral vertebro-costal (OP.7) and the tuberculo-costal (OP.8). The authors of the present work have not tried, depending on guessing, to morphologically relate any of the latter mentioned eight ophidian muscles to an apparantly similar muscle found in lizards. It is beleived in the present work, that such a process of guessing is not scientifically safe enough, and in the case of those muscles other techniques and methods are needed such as embryology and innervation to establish homologies on solid grounds. Speculations similar to those given by GASC (1967) are refused in the present work.

However, it is very noticable that the muscle units whether of a homologized or nonhomologized muscle, are characterized by being of a very complicated nature when compared with the muscle units found in lizards. It was noticed also that in several cases two successive units are connected together by fine bundles of muscle fibres. The latter observation was also noticed by AUFFENBERG (1961 \& 1962). Surely, that morphological complications reflect some functional meaning. In fact, when AUFFENBERG (1961) suggested some evolutionary trends in the different anatomical characteristics of muscle units in snakes, he did not propose the functional significance of those anatomical variations. Further, it is suspected that, in some cases, like the case of the different groups of muscles located on the ribs and are attached to them, those muscle units are one and the same muscle but have multiplied by a process of splitting and laterally shifting.

The over all outlook on the axial musculature of the snake in question shows that the anatomy, distribution of locations, and origins and insertions of the different muscles are all devoted to serve the special type of the serpentine movement.

Some works such as those of MOSAEUR, 1932 \& 1933; AUFFENBERG, 1961 \& 1962; GASC, 1967 and BELLAIRS, 1969, deal with the homologies of certain trunk muscles or groups of muscles of several snakes. In the work of GASC (1967), on the axial musculature of serpents, the nerve supply of each muscle examined is given. The detailed myological studies of AUFFENBERG (1961) on different snake families led him to conclude that the most important trends in the transformation from the basic myological types found in Boidae to the more complex types found in Colubridae are: first, the tendency of the elements fo a median muscle to become connected by a sort of muscular anastomosis with the elements of a muscle just lateral to it, and second, the tendency of another connection between successive elements of a certain muscle with the consiquent result of elongating what could be called a functional unit. Such latter two phenomena were termed "Myological Colubridization".

Assiut Vet.Med.J. Vol. 18, No. 35, 1987. 


\section{V- COMMENTS ON THE MUSCLES DESCRIBED IN THE FIRST FOUR PAPERS OF THE PRESENT SERIES INCLUDING A COMPARISON WITH THE CASE OF LIZARDS}

The examination of the present snake has proved that the lateral connections are morphologically absent but functionally present. For example, the muscle numbered 15 (outer semispinal) and the muscle numbered 16 (dermo-costal) are adjacent and parallel muscles, but they are separated by the longitudinal vertical connective tissue septum (C.S.2). However, branches of two opposite units of the two muscles are attached to both sides of the second vertical connective tissue septum (C.S.2) at dead opposite points, thus functionally but not morphologically verifying the idea of AUFFENBERG (1961). Also, there are some muscle fibres which connect the outer semispinal (15) with the dermo-costal (16) of Tarentola annularis (unpublished work at the Department of Zoology, Assiut University). A feature which may increase th degree of coordination of the works of the two muscles, thus contributing in the elegant trunk movement of that animal. That anatomical and functional feature is similar to the condition found in some snakes and may lead to the same functional feature. The second trend described by AUFFENBERG (1961) about the continuity between the successive units of a muscle is very clear in the present work and one could refer to muscles numberd (15,16 \& 17). Further, the latter author mentioned that in the case of Colubridae, the tendinous arch for the origin of the spinalis and semispinalis (15) is absent, and he also mentioned that in the same family the skeletal insertion of the dermo-costal (16) is also lost. The latter two observations are found in the colubrid snake under investigation.

Sphenodon which is the most primitive saurian example has a strong and efficient system of muscles attached to the ribs and scutes (BAYERLY, 1926). Eight of those muscles are attached on the ribs which enable that animal to perform good trunk movements. In addition, the muscles that extend from the ribs to the scutes may allow the animal to perform snake-like movement during burrowing and locomotion through narrow places. That behaviour is exactly similar to that of snakes. A good example which can show the special efficiency of the musculature of the ribs is when one compare the supracostal muscle of lizards as represented by Uromastyx aegyptia (KHALIL, et al. 1977) and snakes as represented by Psammophis sibilans. In the case of Uromastyx aegyptia the supracostal units (18) are represented by few bundles (not more than four), while in Psammophis sibilans they are represented by a very complex system described in the present work.

The elongation of the outer semispinal units (15) of the snake studied, where the insertion tendons extend over more than thirty vertebrae in the middle of the trunk region enables long segments of the vertebral column to make smooth and wide curves to facilitate the special serpentine movement. On the other hand, in the case of Uromastyx aegyptia (KHALIL, et al. 1977) that muscle is represented by segmented muscle units, each of which nearly covers the length of three successive vertebrae.

\section{REFERENCES}

Auffenberg, W. (1961): Additional remarks on the evolution of trunk musculature in snakes. The American Midland Naturalist. Vol. 65, No. 1, 1-16.

Auffenberg, W. (1962): A review of the trunk musculature in limbless land vertebrates. University of Colorado. Am. Zoologist, 2, 183-190.

Bayerly, T.C. (1926): The myology of Sphenodon punctatum. Stud. Nat. Hist. lowa Univ. Vol. $11(6), 3-51$. 


\section{A. KHALIL, et al.}

Bellairs, A. (1969): The life of reptiles. Vol. 1. Weidenfeld and Nicolson, London.

Gasc, J.P. (1967): Introduction a l'étude de la musculature axiale des Squamates Serpentiformes. Mem. Mus. Nat. Hist. Nat. Paris. 48, 69-125. Khalil, A.; Wahba, M.T. and Shawki, N.A. (1977): The post-cranial myology of Uromastyx aegyptia
(Forskäll).

Mosaeui, W. (1932): On the locomotion of snakes. Science, N.Y. 76, 583-585.

Mosaeur, W. (1935): The myology of the trunk region of snakes and its significance for ophidian taxonomy and phylogeny. Pupl. Univ. Calif. Los.Angeles. 1, 81-120. 
,

, 